\title{
Rapidly growing Epstein-Barr virus-associated pulmonary lymphoma after heart transplantation
}

\author{
M. Schwend*, M. Tiemann**, H.H. Kreipe**, M.R. Parwaresch**, E.G. Kraatz', \\ G. Herrmann++, R.P. Spielmann", J. Barth*
}

Rapidly growing Epstein-Barr virus-associated pulmonary lymphoma after heart transplantation. M. Schwend, M. Tiemann, H.H. Kreipe, M.R. Parwaresch, E.G. Kraatz, G. Herrmann, R.P. Spielmann, J. Barth. CERS Journals Ltd 1994.

ABSTRACT: There is strong evidence to show an association of Epstein-Barr virus (EBV) infection with the development of post-transplant lymphoproliferative disease. We report the rapid development of a malignant lymphoma in a heart transplant recipient, which occurred within less than eight weeks.

The diagnosis of this malignant high grade B-cell lymphoma was established by open lung biopsy, and classified as centroblastic lymphoma of polymorphic subtype. Immunohistochemically, the lymphoma showed reactivity with the B-cell markers L-26 (CD20) and Ki-B5 and with the activation marker Ber-H2 (CD30). Furthermore, an expression of the bcl-2 oncoprotein was detected. Monoclonal JH gene rearrangement was demonstrated by polymerase chain reaction (PCR), indicating monoclonal proliferation of B-blasts.

Although serum EBV immunoglobulin M (IgM) antibodies were negative, the association to an EBV infection could be demonstrated by EBV immunostaining pattern which revealed an expression of the latent membrane protein (LMP) of EBV in the atypical blasts.

The results give clear evidence of an EBV association of this rapidly growing lymphoma developed after heart transplantation.

Eur Respir J., 1994, 7, 612-616.

\author{
Dept of *Internal Medicine, **Hemato- \\ pathology, ${ }^{+}$Cardiovascular Surgery,

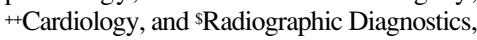 \\ Christian-Albrechts-University of Kiel, Kiel, \\ Germany.
}

Correspondence: J. Barth

I. Medizinische Universitätsklinik

Schittenhelmstr. 12

D-24105 Kiel

Germany

Keywords: Epstein-Barr virus

heart transplantation

pulmonary lymphoma

Received: July 11993

Accepted after revision November 51993
The advances in immunosuppression in the past decade have greatly improved the feasibility of transplantation medicine. Whereas successful immunosuppression prevents rejection of the transplant and maintains the function of the organ, it also is the basis of transplantation associated complications, which mostly affect the lung [1]. In permanent contact with the external milieu, the lung is especially prone to infections in immunosuppressed patients [2]. Furthermore, an increase of primary and secondary malignancies of the lung occurs in transplantation patients, which may cause considerable differential diagnostic difficulties due to rapid tumour growth or unusual clinical and radiographic manifestations $[1,2]$. Although the incidence of common carcinomas is not increased, there is a considerable increase of lymphomas occurring after transplantation [3, 4]. The Epstein-Barr virus (EBV) plays a crucial role in the pathogenesis of post-transplantational lymphoproliferative disease [5-8].

Before the introduction of modern immunohistochemical and molecular biological techniques with appropriate monoclonal antibodies and gene probes, it was difficult to characterize the malignant tumour and to support the proposed association of post-transplant lymphomas to an EBV infection.
We report the case of a rapidly growing pulmonary lymphoma classified by immunohistochemical methods and polymerase chain reaction (PCR) analysis.

\section{Case report}

A 51 year old male with a New York Heart Association class IV dilated cardiomyopathy underwent orthotopic heart transplantation in September 1990. Postoperatively, immunosuppressive therapy was started with antithymocyte globulin, followed by a triple combination of cyclosporin A, azathioprine and methylprednisolone. An endomyocardial biopsy performed eight weeks after transplantation revealed no histological evidence of allograft rejection, and a chest roentgenogram displayed no abnormalities of the lung structure. After another two months, myocardial biopsy still failed to display any evidence of a rejection, whereas a subsequent chest $\mathrm{X}$-ray revealed symmetrical, patchy infiltrates in both lungs, mainly occurring in the middle and lower fields (fig. 1). The patient was free of symptoms; specifically, he had no history of fever, weight loss, nocturnal sweat, or dyspnoea.

Physical examination demonstrated only slight high pitched crackles over both lungs. The erythrocyte 


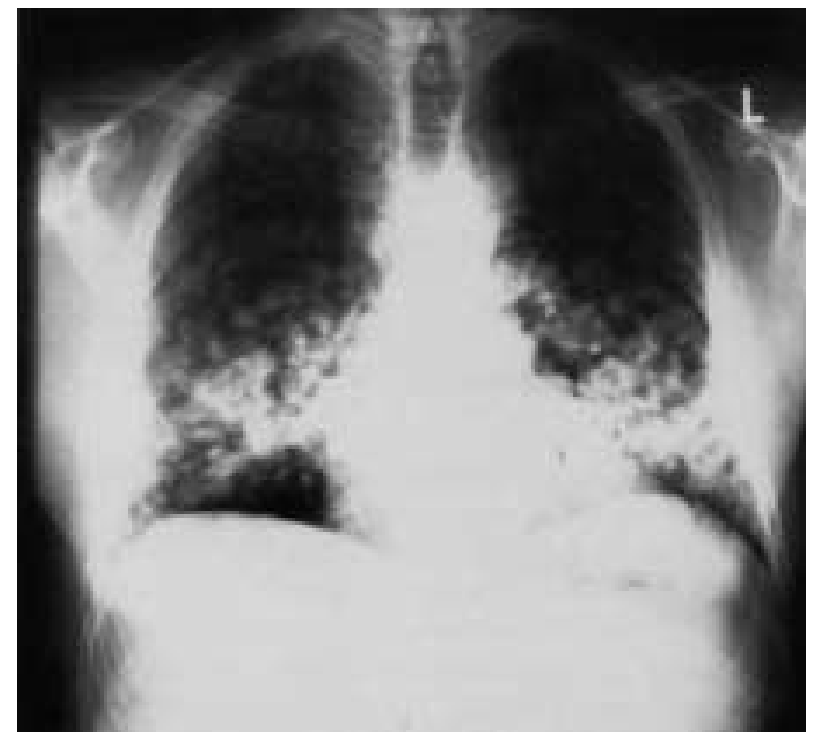

Fig. 1. - Chest X-ray after a routine myocardial biopsy, accidentally demonstrating infiltrates over both lungs.

sedimentation rate $(\mathrm{ESR})$ was $50 / 77 \mathrm{~mm}$, haemoglobin $11.2 \mathrm{~g} \cdot \mathrm{dl}^{-1}$, urea $92.6 \mathrm{mg} \cdot \mathrm{dl}^{-1}$, and creatinine $1.69 \mathrm{mg} \cdot \mathrm{dl}^{-1}$. Lactate dehydrogenase was increased at $274 \mathrm{U} \cdot l^{-1}$ (normal $\left.<240 \mathrm{U} \cdot l^{-1}\right)$. Normal values were found for other serum enzymes, serum electrophoresis and the tumour markers alpha-fetoprotein (AFP), carbohydrate antigenic determinant 19-9 (CA 19-9) and carcinoembryonic antigen (CEA). Paraproteins were not detectable in serum and urine. Sputum and gastric juice samples were free from tuberculosis bacteria. Antibody screening was negative for EBV immunoglobulin $\mathrm{M}$ (IgM) and showed no evidence of a fresh EBV infection; however, it revealed a past primary EBV infection. From cultures and serological tests there was no evidence of a current infection with other pneumotropic viruses, Candida, Aspergillus, Legionella pneumophila or Mycoplasma. A computed tomography (CT)-scan of the thorax visualized multiple pulmonary nodules, mainly in the middle fields (fig. 2).

Lung function tests revealed a restrictive pattern, with a decreased vital capacity of $3.2 l$ (predicted $4.47 l$ ) and a decreased arterial oxygen tension $\left(\mathrm{PaO}_{2}\right)$ of $54 \mathrm{mmHg}$ $(7.2 \mathrm{kPa})$. The single-breath diffusing capacity of the lungs for carbon monoxide (DLCO) was reduced to 3.67 $\mathrm{mmol} \cdot \mathrm{min}^{-1} \cdot \mathrm{kPa}^{-1}$ (46\% predicted). Fibreoptic bronchoscopy showed a low grade inflammation without circumscript alterations of the bronchial system. Transbronchial biopsies revealed an interstitial fibrosis without evidence of a specific pneumonia or malignancy.

The bronchoalveolar lavage fluid contained 64\% macrophages, $35 \%$ lymphocytes and $1 \%$ granulocytes. The analysis of lymphocyte subpopulations displayed $89 \%$ CD3, 44\% CD4, 48\% CD8, and 4\% CD19 positive Blymphocytes. The CD4/CD8 ratio was 0.92 . Immunostaining for pneumocystis carinii and cytomegalovirus (CMV) early antigen was negative. Further investigations, including abdominal ultrasound and bone marrow biopsies, revealed no pathological findings leading to a diagnosis.

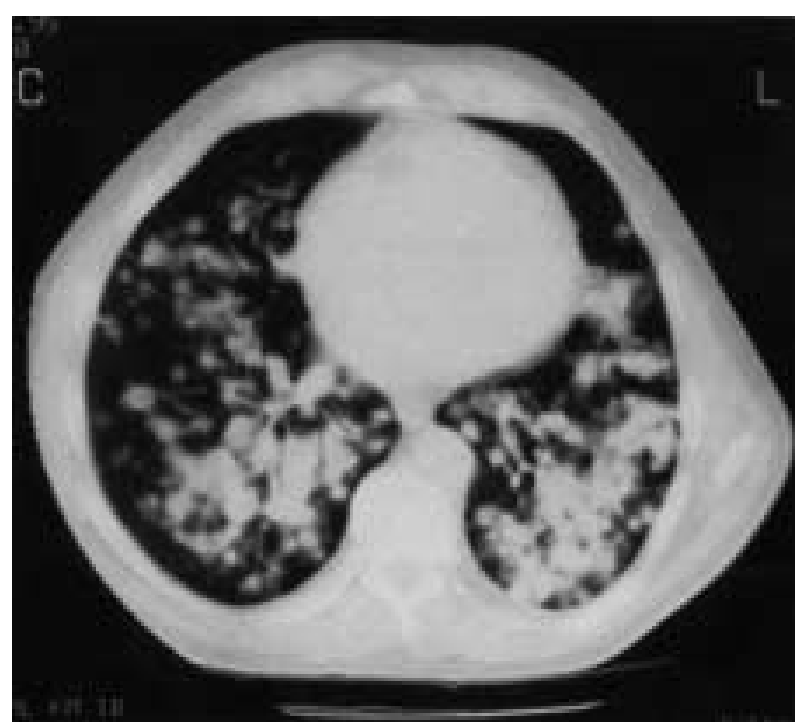

Fig. 2. - Computer tomography of the thorax showing multiple pulmonary nodules with preference to the middle fields of both lungs.

Open lung biopsy demonstrated a high grade malignant B-cell lymphoma, which was classified immunohistochemically as a centroblastic lymphoma of polymorphic subtype (high grade germinal centre lymphoma). A monoclonal light chain expression was not found.

Azathioprine therapy was stopped and the dosage of cyclosporin A was decreased. Subsequently, combination chemotherapy with cyclophosphamide, doxorubicin, vincristine and prednisolone was initiated. The patient died unexpectedly because of cardiorespiratory failure shortly after the first therapy cycle was completed. Permission for autopsy was not obtained.

\section{Immunohistochemical and molecular analysis}

\section{Material and methods}

Immunohistochemistry of lymphoma tissue was performed with the alkaline phosphatase and anti-alkaline phosphatase (APAAP) staining system, according to CORDELl et al. [9], with a monoclonal antibody against EBV latent membrane antigen (LMP-1) encoded by the $\mathrm{BNLF}_{1}$ gene of the EBV virus, which is expressed in EBV-infected cells (Dako, Hamburg, FRG) [10]. Furthermore, staining with the bcl-2 oncoprotein antibody (Dako, Hamburg, FRG) was performed, marking an antigen which is expressed in germinal centre cell lymphoma with the 14;18 translocation [11]. The B-cell nature of the lymphoma was demonstrated by staining with the monoclonal B-cell antibodies Ki-B5 [12] (Parwaresch, Kiel, FRG) and L-26 (CD20, Dako, Hamburg, FRG) [13]. An anti CD3 polyclonal antibody was also obtained (Dako, Hamburg, FRG), whereas the Ber-H2 monoclonal antibody, which recognizes an activation antigen (CD30), also expressed in EBV infected cells, was obtained by Stein (Berlin, FRG) [14]. Deoxyribonucleic acid (DNA) 
was studied by polymerase chain reaction (PCR) technique for IgH rearrangement. DNA was extracted from paraffin blocks, as described by WAN et al. [15]. After PCR, mineral oil was removed and samples were extracted with chloroform. Five microlitres of each sample was loaded onto a polyacrylamide gel for $100 \mathrm{~min}$ at $400 \mathrm{~V}$ over a temperature gradient of $\mathrm{T}_{1} 10^{\circ} \mathrm{C}$ and $\mathrm{T}_{2}$ $60^{\circ} \mathrm{C}$. After electrophoresis, fractions were stained using a silver-staining procedure, according to ROSENBAUM and RIESNER [16].

\section{Results and interpretation}

Immunohistochemical investigations revealed an expression of the activation antigen CD30 and of the bcl-2 oncoprotein in a minority of cells (fig. 3). Bcl-2 expression is associated with the production of an inner mitochondrial membrane protein that blocks programmed cell death [17], which results in a growth advantage of bcl-2 positive lymphoma cells.

Additionally, LMP could be detected in larger, Hodgkincell-like immunoblasts (fig. 4), indicating the EBVassociation of the lymphoma [10].

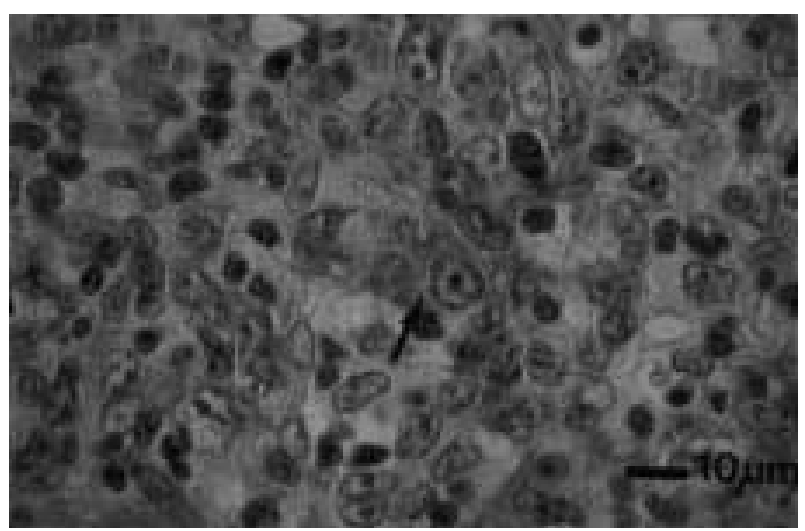

Fig. 3. - Alkaline phosphatase and anti-alkaline phosphatase (APAAP) immunostaining of lymphoma cells with a monoclonal antibody against bcl-2 oncoprotein (black arrow), which is expressed in germinal centre cell lymphoma with the $14 ; 18$ translocation. (Scale bar $=10 \mu \mathrm{m}$ ).

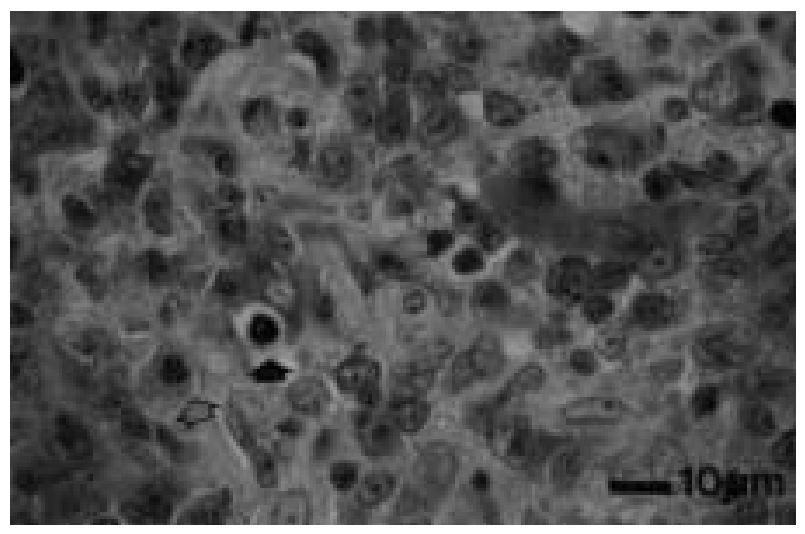

Fig. 4. - APAAP immunostaining of lymphoma cells with a monoclonal antibody against latent membrane protein (LMP) expressed in Epstein-Barr virus (EBV)-infected cells. An apoptosis of a LMPnegative cell is shown (black arrow) as well as a mitotic cell (white arrow). (Scale bar $=10 \mu \mathrm{m})$.
Table 1. - Immunoreactivity pattern of lymphoma cells

\begin{tabular}{llll}
\hline Antibody & Cluster & Immunoreactivity & Source \\
\hline L-26 & CD20 & + & Dako, Hamburg, FRG \\
Ki-B5 & - & + & Parwaresch, Kiel, FRG \\
Ber-H2 & CD30 & + & Stein, Berlin, FRG \\
Anti-CD3 & CD3 & - & Dako, Hamburg, FRG \\
bcl-2 & - & + & Dako, Hamburg, FRG \\
LMP & - & + & Dako, Hamburg, FRG
\end{tabular}

LMP: latent membrane protein.

The regular B-cell antigens, Ki-B 5 and L-26, could be demonstrated on all atypical blasts, including small centroblasts. The immunostaining pattern of lymphoma cells is summarized in table 1. After PCR with primers specific for heavy chain consensus sequences [15], using temperature gradient gel electrophoresis, one monoclonal band was detected, which has to be interpreted as monoclonal proliferation of B-blasts [15].

\section{Discussion}

Pulmonary infections are the most frequent and important complications after heart transplantation. According to recent studies, they occur with a frequency of $24-40 \%$ $[2,18]$. They normally develop within the first 3-4 months after transplantation, and they often show a lethal course at this stage [19]. Even after this period, pulmonary infections still constitute a major complication of heart transplantation. In this particular case, the radiographic alterations developed within a few weeks, so that a possible infectious cause had to be taken into consideration, even if no clinical symptoms were detectable. The clinical course and the diagnostic procedures, including BAL, transbronchial biopsies and serological findings, ruled out a current infectious disease, but they did not allow a definitive diagnosis. The CT-scan of the lungs pointed to a malignant process; therefore, an open lung biopsy was performed and the diagnosis of this high grade malignant B-cell lymphoma was established.

Organ recipients after allotransplantation carry a strongly increased risk of malignancy [20-22]. Whereas, the incidence of common carcinomas like bronchial, breast, colon, or prostate carcinoma is not increased, there is an increase of particular malignancies, such as the hepatobiliary carcinoma, the Kaposi-sarcoma, and, most of all, the lymphomas. According to recent studies, the highest rate of lymphomas is found in heart and heart/lung transplanted patients, with a 3.5-7\% risk of developing a lymphoproliferative disease after transplantation [3, 4]. These lymphomas are frequently (about 30\%) located in the lungs, which is an uncommon location otherwise. The risk of a post-transplantation lymphoproliferative disorder increases with the intensification of the immunosuppressive therapy [23]. In this case, the patient initially received antithymocyte globulin, followed by a long-term triple combination of cyclosporin A, azathioprine and methylprednisolone. If cyclosporin $\mathrm{A}$ is a part of the immunosuppressive regime, lymphomas are more 
frequent and they occur earlier in the post-transplantation period. The short time of 10 months between transplantation and clinical appearance of this lymphoma corresponds to the findings of epidemiological studies, which showed that lymphomas most frequently occur within a few months up to a year after initiating the immunosuppressive therapy with cyclosporin $[3,22]$. In contrast, the average period of lymphoma manifestation after conventional immunosuppressive therapy was found to be 48 months.

Post-transplantation lymphoproliferative disorders resemble, in many aspects, lymphomas occurring in congenital or acquired immunodeficiency states. Most of them appear as B-cell-non-Hodgkin lymphomas with extranodal localization in about $70 \%$ of all cases. The most frequent localization is the gastrointestinal tract, where the small intestine may be affected. The tonsils, liver, spleen, heart and lungs are other sites of manifestation $[24,25]$.

Both monoclonal and polyclonal tumours occur. Monoclonal JH gene rearrangement was detected by PCR method to show monoclonality of B-blasts, in this case of post-transplantation lymphoma.

The Epstein-Barr virus plays a leading role in the pathogenesis of post-transplantation lymphoproliferative disease. In most cases, serological evidence of a primary or reactivated EBV-infection is seen $[3,6,7,26,27]$. The EBV genoma was found in tumour tissue in 7 out of 8 and in 9 out of 10 cases, respectively, using DNAhybridization techniques [27, 28]. EBV transformation associated genes are frequently expressed in the tumour tissue and have been detected using immunohistochemistry [8]. Our patient showed a serologically detected postprimary EBV infection. IgM antibodies were negative. An EBV association of the lymphoma was proved by immunostaining with a monoclonal antibody against the EBV latent membrane antigen [10].

It has been proposed that immunosuppression permits an uncontrolled proliferation of EBV-infected Blymphocytes resulting in an oligoclonal B-cell hyperplasia and, ultimately, in a monoclonal B-cell tumour [24]. Furthermore, studies of the endonuclease restriction pattern of EBV genomic termini revealed that most tumours contained homogeneous episomal EBV DNA [29]. These findings emphasize the role of EBV infection in tumourogenesis, and indicate that the tumour growth starts from a single EBV infected B-cell early in the course of the disease with later clonal expansion.

The therapy consists of a reduction of the intensity of immunosuppression, the interruption of EBV replication by administration of acyclovir, chemotherapy, radiotherapy and surgical intervention, depending on staging and grading of the tumour $[5,26,27]$. It is noteworthy that an exclusive reduction of the immunosuppressive therapy and the resulting recovery of the immune state frequently leads to a decrease of the tumour size or a complete remission. Acyclovir therapy appears to be promising in cases of an oligoclonal lymphoma associated with an EBV infection [6, 24]. An alternative approach to the treatment of polyclonal lymphoproliferative disorders has recently been published [30]. This involved the use of monoclonal anti-B cell antibodies and showed good results.

\section{References}

1. Ettinger NA, Trulock EP. Pulmonary considerations of organ transplantation. Part 3. Am Rev Respir Dis 1991; 144: 433-451.

2. Austin JHM, Schulman LL, Mastrobattista JD. Pulmonary infection after cardiac transplantation. Clinical and radiologic correlations. Radiology 1989; 172: 259-265.

3. Armitage JM, Kormos RL, Stuart RS, et al. Posttransplant lymphoproliferative disease in thoracic organ transplant patients. Ten years of cyclosporine-based immunosuppression. J Heart Lung Transplant 1991; 6: 877-886.

4. Pennock JL, Oyer PE, Reitz BA, et al. Cardiac transplantation in perspective for the future. Survival, complications, rehabilitation and costs. J Thorac Cardiovasc Surg 1982; 83: 168-177.

5. Dummer JS, Bound LM, Singh G, Atchinson RW, Kapadia $\mathrm{SB}$, Ho M. Epstein-Barr virus-induced lymphoma in a cardiac transplant recipient. Am J Med 1984; 77: 179-184.

6. Hanto DW, Frizzera G, Gajl-Peczalska KJ, Balfour HH, Simmons RL, Najarian JS. Acyclovir therapy of EpsteinBarr virus induced post-transplant lymphoproliferative diseases. Transplant Proc 1985; 17: 89-92.

7. Hanto DW, Frizzera G, Gajl-Peczalska KJ, Simmons RL. Epstein-Barr virus, immunodeficiency, and B-cell lymphoproliferation. Transplant 1985; 39: 461-472.

8. Young L, Alfieri C, Hennessy K, et al. Expression of Epstein-Barr virus transformation-associated genes in tissues of patients with EBV lymphoproliferative disease. $N$ Engl J Med 1989; 321: 1080-1083.

9. Cordell JL, Falini B, Erber WN, et al. Immunoenzymatic labeling of monoclonal antibodies using immune complexes of alkaline phosphatase and monoclonal antialkaline phosphatase (APAAP complexes). J Histochem Cytochem 1984; 2: 219-229.

10. Rowe M, Evans HS, Young LS, Hennesy K, Kieff E, Rickinson AB. Monoclonal antibodies to the latent membrane protein of Epstein-Barr virus reveal heterogeneity of the protein and inducible expression in virustransformed cells. J Gen Virol 1987; 68: 1575-1586.

11. Cleary ML, Smith SD, Skar J. Cloning and structural analysis of cDNAs for bcl-2 and a hybrid bcl-2/immunoglobulin transcript resulting from the $\mathrm{t}(14 ; 18)$ translocation. Cell 1986; 47: 19-28.

12. Hansmann ML, Wacker HH, Graller J, et al. Ki-B5, a monoclonal antibody to normal and neoplastic human Bcells in routine paraffin sections. Blood 1991; 77: 809-817.

13. Ishii Y, Takami T, Yuase H, Takei T, Kikuchi K. Two distinct antigen systems in human B-lymphocytes: identification of cell surface and intracellular antigens using monoclonal antibodies. Clin Exp Immunol 1984; 58: 183-192.

14. Schwarting R, Gerdes J, Dürkop H, Falini B, Pileri S, Stein H. Ber-H2: a new anti-Ki-1 (CD-30) monoclonal antibody directed at a formol-resistant epitope. Blood 1989; 74: 1678-1689.

15. Wan JH, Trainor KJ, Brisco MJ, Morley AA. Monoclonality in B-cell lymphoma detected in paraffin wax embedded sections using the polymerase chain reaction. J Clin Pathol 1990; 43: 888-890.

16. Rosenbaum V, Riesner D. Temperature-gradient gel electrophoresis. Thermodynamic analysis of nucleic acids 
and proteins in purified form and in cellular extracts. Biophys Chem 1987; 26: 235-246.

17. Hockenbery D, Nunez G, Milliman C, Schreiber RD, Korsmeyer SJ. Bcl-2 is an inner mitochondrial membrane protein that blocks programmed cell death. Nature 1990; 348: 334-336.

18. Gorensek MJ, Stewart RW, Keyus TF, Mehta AC, McHenry $\mathrm{MC}$, Goormastic M. A multivariate analysis of risk factors for pneumonia following cardiac transplantation. Transplant 1988; 46: 860-865.

19. Andreone PA, Olivari MT, Elick B, et al. Reduction of infectious complications following heart transplantation with triple drug therapy. J Heart Transplant 1986; 5: 336-340.

20. Penn I, Hammond W, Brettschneider L, Starzl TE. Malignant lymphomas in transplantation patients. Transplant Proc 1969; 1: 106-112.

21. Penn I. Lymphomas complicating organ transplantation. Transplant Proc 1983; 15: 2790-2797.

22. Penn I. Cancers complicating organ transplantation. $N$ Engl J Med 1990; 323: 1767-1769.

23. Swinnen LJ, Costanzo-Nordin MR, Fisher SG. Increased incidence of lymphoproliferative disorder after immunosuppression with the monoclonal antibody OKT3 in cardiac transplant recipients. N Engl J Med 1990; 323: $1723-1728$.
24. Nalesnik MA, Makowka L, Starzl TE. The diagnosis and treatment of post-transplant lymphoproliferative disorders. Curr Probl Surg 1988; 25: 365-472.

25. Weintraub J, Warnke RA. Lymphoma in cardiac allotransplant recipients. Transplant 1982; 33: 347-351.

26. Hanto DW, Sakamoto K, Purtilo D, Simmons RL, Najarian JS. The Epstein-Barr virus in the pathogenesis of posttransplant lymphoproliferative disorder. Surgery 1985; 90: 204-213.

27. Starzl TE, Nalesnik MA, Porter KA. Reversibility of lymphomas and lymphoproliferative lesions developing under cyclosporin steroid therapy. Lancet 1984; i: 583587.

28. Cleary ML, Warnke R, Skar J. Monoclonality of lymphoproliferative lesions in cardiac-transplant recipients: clonal analysis based on immunoglobulin-gene rearrangements. N Engl J Med 1984; 310: 477-482.

29. Patton DF, Wilkowski CW, Hanson CA, et al. EpsteinBarr virus determined clonality in post-transplant lymphoproliferative disease disease. Transplant 1990; 49: 1080-1084.

30. Fischer A, Blanche S, Le Bidois J, et al. Anti-B-cell monoclonal antibodies in the treatment of severe B-cell lymphoproliferative syndrome following bone marrow and organ transplantation. N Engl J Med 1991; 324: $1451-1454$. 